ADA Notice

For individuals with sensory disabilities, this document is available in alternate formats. For information call (916) $654-6410$ or TDD (916) $654-3880$ or write Records and Forms Management, 1120 N Street, MS-89, Sacramento, CA 95814.

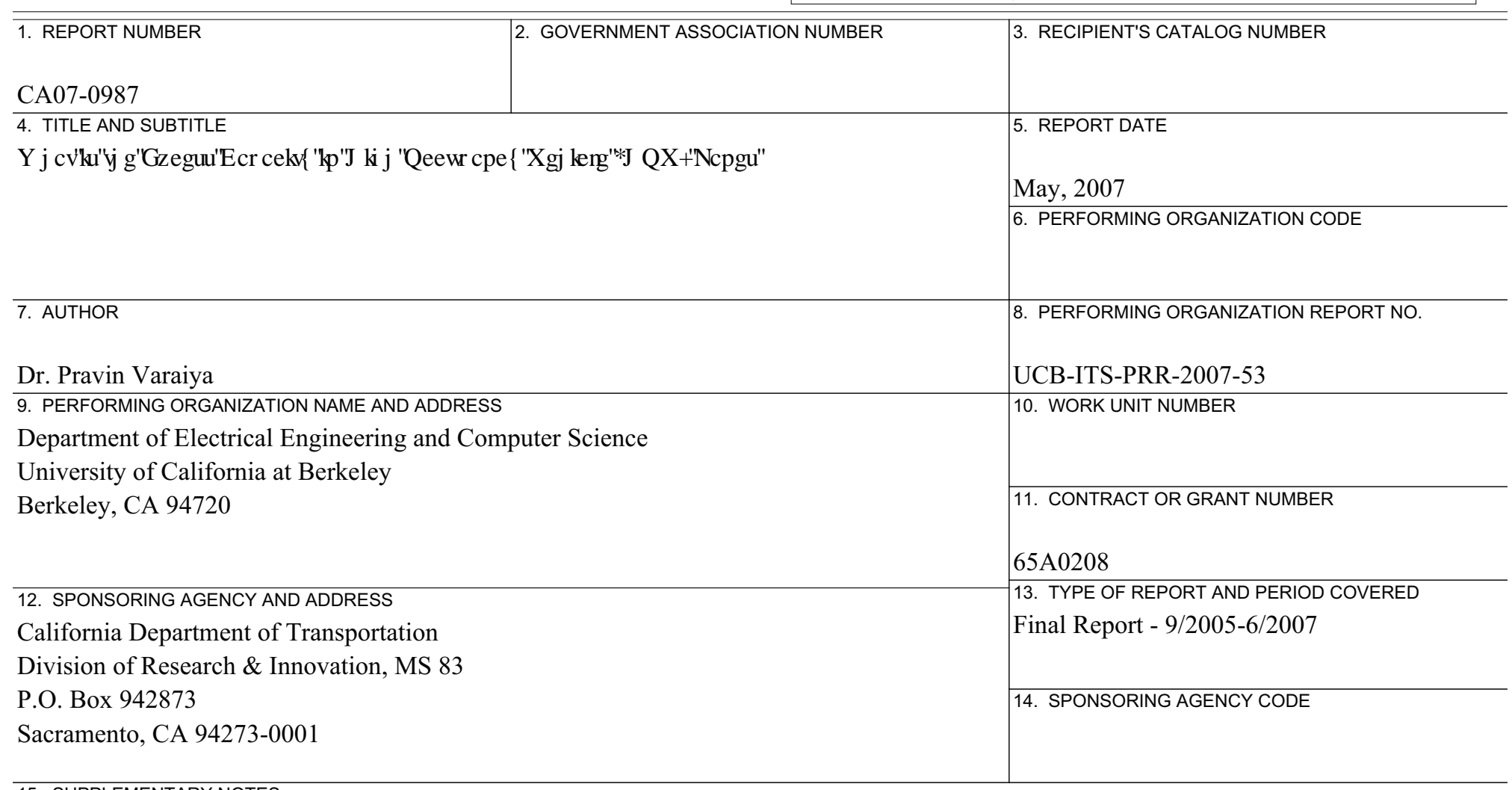

15. SUPPLEMENTARY NOTES

\begin{abstract}
16. ABSTRACT
An extensive evaluation of the effectiveness of California's HOV system was performed utilizing data collected from traffic sensors. 1,700 inductive loop-based vehicle detector stations (VDS) monitor 780 out of 1,171 lane-miles of California's HOV system. The data utilized for this evaluation was reliable data collected 5-6PM peak hour speed and flow measurements from 700+ stations for 128 weekdays, JanuaryJune, 2005; data from the remaining stations were unreliable. Data from a station are considered reliable if the station reports good hourly data for more than half of all weekdays considered. Data are considered good if the loop measurements pass the statistical tests implemented in
\end{abstract} PeMS.

The results of this research lead to four major conclusions. (1) Since it operates as a single lane freeway, an HOV lane suffers a $20 \%$ capacity loss compared with multi-lane freeways. (2) HOV lanes are either under-utilized or suffer degraded operations. (3) HOV lanes do not measurably increase car-pooling. (4) HOV lanes do not reduce overall congestion in a reasonably well-managed system. Researchers recommend operating the existing freeway system more efficiently because much more is to be gained by doing so than by adding HOV lanes. Indeed, efficient operations will reduce the value of HOV lanes, which will become under-utilized. Also, despite the negative findings, HOV facilities can play an important role in a well-managed overall freeway system in California.

\section{KEY WORDS}

HOV, vehicle detector stations, VDS, under-utilized, single lane, multi-lane, data, PeMsm, high occupancy vehicle, lane-miles, freeway system, California
20. NUMBER OF PAGES 23

\section{DISTRIBUTION STATEMENT}

No restrictions. This document is available to the public through the

National Technical Information Service, Springfield, VA 22161 


\section{DISCLAIMER STATEMENT}

This document is disseminated in the interest of information exchange. The contents of this report reflect the views of the authors who are responsible for the facts and accuracy of the data presented herein. The contents do not necessarily reflect the official views or policies of the State of California or the Federal Highway Administration. This publication does not constitute a standard, specification or regulation. This report does not constitute an endorsement by the Department of any product described herein.

For individuals with sensory disabilities, this document is available in alternate formats. For information, call (916) 654-8899, TTY 711, or write to California Department of Transportation, Division of Research, Innovation and System Information, MS-83, P.O. Box 942873, Sacramento, CA 94273-0001. 
CALIFORNIA PATH PROGRAM

INSTITUTE OF TRANSPORTATION STUDIES

UNIVERSITY OF CALIFORNIA, BERKELEY

\title{
Effectiveness of California's High Occupancy Vehicle (HOV) System
}

\author{
Pravin Varaiya
}

\section{California PATH Research Report \\ UCB-ITS-PRR-2007-5}

This work was performed as part of the California PATH Program of the University of California, in cooperation with the State of California Business, Transportation, and Housing Agency, Department of Transportation, and the United States Department of Transportation, Federal Highway Administration.

The contents of this report reflect the views of the authors who are responsible for the facts and the accuracy of the data presented herein. The contents do not necessarily reflect the official views or policies of the State of California. This report does not constitute a standard, specification, or regulation.

Final Report for Task Order 6301

May 2007

ISSN 1055-1425 


\title{
Effectiveness of California’s High Occupancy Vehicle (HOV) System Final Report for PATH TO 6301
}

\author{
Pravin Varaiya \\ Department of Electrical Engineering and Computer Science \\ University of California, Berkeley CA 94720 \\ Tel: (510) 642-5270, Fax: (510) 642-7815 \\ varaiya@eecs.berkeley.edu
}

April 30, 2007

\begin{abstract}
This is the most extensive empirical evaluation of the effectiveness of California's HOV system based on data collected from traffic sensors. The evaluation leads to four major conclusions. (1) Since it operates as a single lane freeway, an HOV lane suffers a $20 \%$ capacity loss compared with multi-lane freeways. (2) HOV lanes are either under-utilized or suffer degraded operations. (3) HOV lanes do not measurably increase car-pooling. (4) HOV lanes do not reduce overall congestion in a reasonably well-managed system.
\end{abstract}

Keywords: HOV effectiveness; carpooling; HOT lanes; San Francisco Bay Area; congestion 


\section{Executive Summary}

California's HOV system comprises 1,171 lane-miles, with 803 miles in the South and 366 in the North. This study analyzes peak period traffic data from hundreds of loop detectors over many months in order to evaluate the system's effectiveness. The study finds:

(1) HOV lanes are underutilized: $81 \%$ of HOV detectors measure flows below 1,400 vehicles per hour per lane (vphpl) during the PM peak hour;

(2) Many HOV lanes suffer degraded operations: 18 percent of all HOV-miles during the AM peak hour and 32 percent during the PM peak hour have speeds below $45 \mathrm{mph}$ for more than 10 percent of weekdays;

(3) HOV lanes suffer a 20\% capacity penalty: HOV lanes achieve a maximum flow of 1,600 vphpl at $45 \mathrm{mph}$; in contrast general purpose lanes record maximum flows above 2,000 vphpl at $60 \mathrm{mph}$

(4) HOV lanes offer small travel time savings: The mean savings over a random 10-mile route traveling on an HOV lane vs. general purpose (GP) lane 1 is 1.7 minutes, the median is 0.7 minutes; however, HOV travel times are more reliable;

(5) Travel time savings do not provide a statistically significant carpooling incentive;

(6) A system with one HOV lane and three general purpose lanes carries the same number of persons per hour as a system with four general purpose lanes;

(7) HOV lanes reduce overall congestion slightly when the general purpose lanes are allowed to become congested.

Despite these findings, HOV facilities can play a useful role in a well-managed overall freeway system in California. In particular, they can be useful if there is a significant number of buses or vanpools; as a 2-lane HOV/HOT facility, which eliminates 'snails' (low speed vehicles) and the resulting capacity loss; and, with efficient metering, as a HOV/HOT bypass at the on-ramps.

\section{Introduction}

In 2005 California's HOV system comprised 1,171 HOV lane-miles (2\% of the system's total) with 803 miles in the South and 366 in the North. Only 37 miles in the South and 32 miles in the North are restricted to $3+$ passenger vehicles, the rest admit $2+$ vehicles.

The design and operation of HOV facilities vary across the State. Virtually all have a single lane. ${ }^{1}$ (The HOV lane is lane 1 , the innermost lane, adjacent to the median.) In the South, the HOV lane is often separated by a striped buffer, with gaps for entry and exit. Being nearly twice as wide, a buffered HOV lane is more expensive than a general purpose (GP) lane. In the North, HOV lanes are not separated, and vehicles may enter or exit at any place.

In the South, most HOV restrictions are in place 24 hours of the day. In the North, HOV restrictions are time-actuated: lane 1 is restricted to carpools on weekdays, generally during 5-9 AM and 4-7 PM; at other times it is a GP lane. A few HOV facilities carry a significant number of buses and vanpools.

The HOV system's goals are to increase the people-moving capacity of the freeway system by encouraging carpooling; reduce overall congestion; provide travel time savings to HOV users;

\footnotetext{
${ }^{1}$ Notable exceptions are the 15-mile two-lane reversible I-15 HOT facility and the 10-mile two-lane SR-91 HOT expressway.
} 
increase system efficiency by allowing HOVs to bypass congestion; and decrease emissions [1, p.3].

This paper summarizes an empirical study of the HOV system's effectiveness, based on peak period traffic data from hundreds of loop detectors over several months. ${ }^{2}$ The study addresses the following aspects:

(1) Utilization of HOV lanes;

(2) Congestion in HOV lanes;

(3) Capacity of HOV lanes;

(4) Travel time savings in HOV lanes;

(5) Effectiveness of HOV lanes in inducing carpooling;

(6) Effect of HOV lanes on overall (HOV and GP lanes) congestion.

Subsequent sections present empirical analyses of these aspects.

\section{Under-utilization and Degraded Operation}

1,700 inductive loop-based vehicle detector stations (VDS) monitor 780 out of 1,171 lane-miles of California's HOV system. We collect reliable 5-6PM peak hour speed and flow measurements from $700+$ stations for 128 weekdays, January-June, 2005; data from the remaining stations were unreliable. Data from a station are considered reliable if the station reports good hourly data for more than half of all weekdays considered. Data are considered good if the loop measurements pass the statistical tests implemented in PeMS and described in its 'help' pages [2] and in [22]. The 'unreliable' stations are distributed across all HOV facilities [5], so the stations included in the study are unlikely to present location bias. The six month-long data set overcomes day-ofweek bias. The resulting 86,831 data samples yield the joint probability histogram of HOV speed and flow.

\footnotetext{
${ }^{2}$ The data are available at the PeMS website [2].
} 


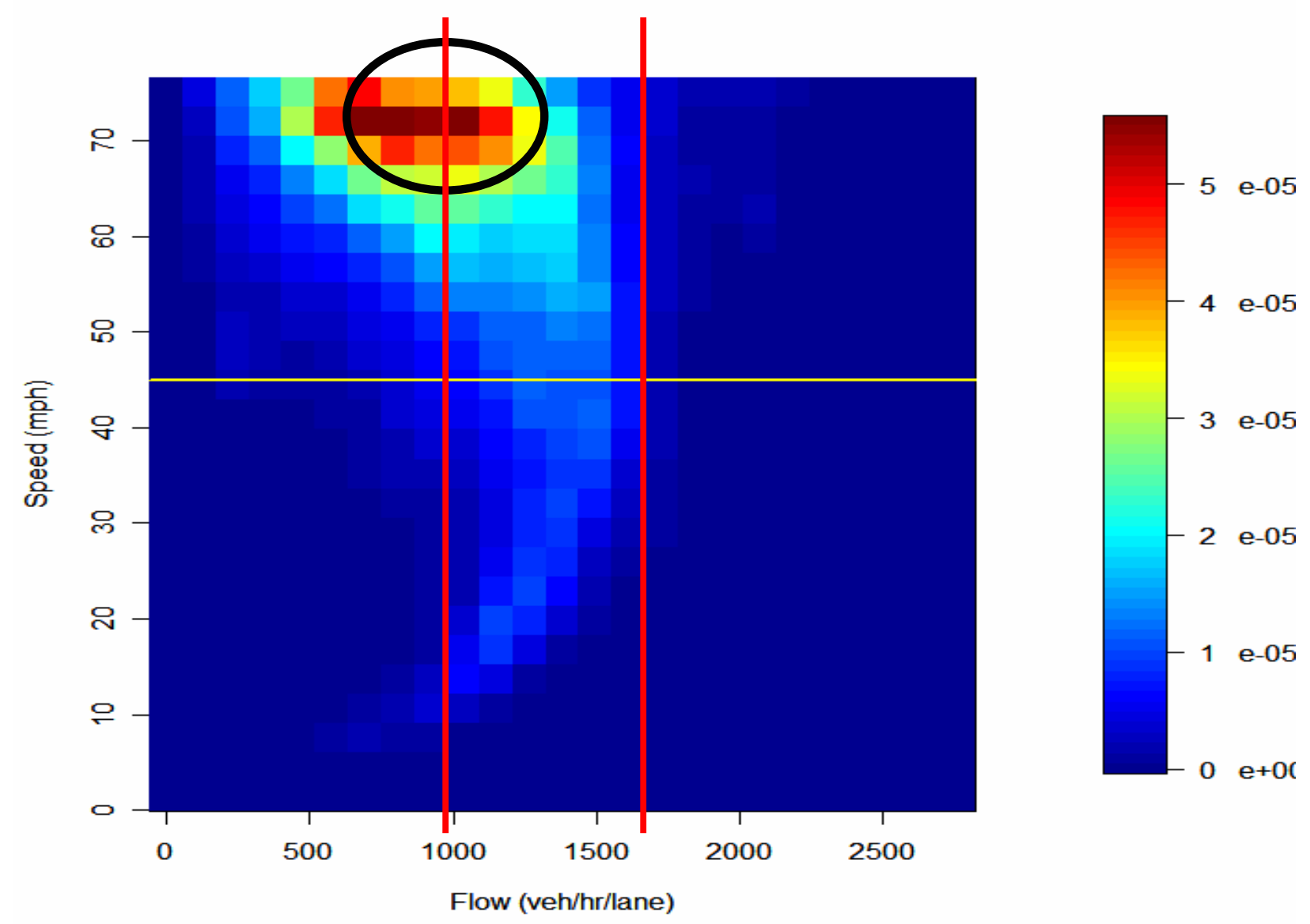

Figure 1 Probability histogram of speed and flow at 700+ HOV loops, 5-6PM, Jan-June, 2005.

The 'heat' plot of Figure 1 displays this probability histogram. One sees that

- The mode of the distribution occurs at a speed of $70 \mathrm{mph}$ and a flow of $900 \mathrm{vphpl}$;

- The maximum flow is 1,600 vphpl at $45 \mathrm{mph}$ : 92\% of the samples have flows under 1,600 vphpl;

- $30 \%$ of the samples show peak PM flow under 800 vphpl.

\begin{tabular}{|c|c|c|c|c|}
\hline District & $\begin{array}{c}\text { Flow } \leq \mathbf{8 0 0} \text { vphpl } \\
\mathbf{( \% )}\end{array}$ & $\begin{array}{c}\text { Flow } \geq \mathbf{1 4 0 0} \text { vphpl, } \\
\text { speed } \mathbf{4} \mathbf{4 5} \mathbf{~ m p h} \mathbf{( \% )}\end{array}$ & $\begin{array}{c}\text { Flow } \leq \mathbf{1 4 0 0} \\
\text { vphpl (\%) }\end{array}$ & $\begin{array}{c}\text { Speed } \leq \mathbf{4 5} \text { mph } \\
\mathbf{( \% )}\end{array}$ \\
\hline 12 & 20 & 17.6 & 77 & 16 \\
\hline 8 & 15 & 12 & 79 & 19 \\
\hline 7 & 38 & 5.7 & 89 & 25 \\
\hline 4 & 33 & 15 & 81 & 6.5 \\
\hline 3 & 35 & 21 & 55 & 37 \\
\hline Statewide & 30 & 15 & 81 & 17 \\
\hline
\end{tabular}

Table 1 Statistics of HOV flows and speeds, by Caltrans district. 
Table 1 lists summary statistics after disaggregating these data by Caltrans district. The statistics support the conclusion that many HOV segments are under-utilized. Caltrans considers HOV lane capacity (LOS-C) to be 1,650 vphpl [3], but $80 \%$ of the samples have flows under 1,400 vphpl (of which $8 \%$ show speeds below $45 \mathrm{mph}$, indicating congestion), and $30 \%$ have flows under 800 vphpl.

Under-utilization of the HOV system prompted the 2005 legislation granting 75,000 SOV hybrid vehicles access to HOV facilities. In order to admit SOV hybrids federal law requires that the facility not be 'degraded': A facility is considered degraded if vehicle speed drops below $45 \mathrm{mph}$ for 10 percent of the peak hours during a six-month period [4, Sec. 1121]. Many California HOV lanes are degraded.

From Table 1, 17\% of the samples exhibit speeds below $45 \mathrm{mph}$ during the PM peak. A more detailed study [5] stratifies these data by HOV segments and finds that "a substantial portion of HOV locations in California is already degraded ... Overall, 18 percent of all HOV-miles are degraded during the AM peak and 32 percent are degraded during the PM peak."

The degraded HOV locations are distributed across most HOV facilities, making it difficult to permit hybrid SOV access to under-utilized portions of the HOV system, while denying access to its degraded portions. Thus, it is impractical to admit SOV hybrids while conforming to the federal requirement. ${ }^{3}$ (The same difficulty will prevent conversion of an existing HOV lane to HOT operation.)

The seeming paradox of California's system is that in most HOV lanes there are portions that are under-utilized and other portions that are congested (degraded). This paradox is resolved upon observing that HOV lanes suffer a $20 \%$ capacity loss, in comparison with general purpose lanes.

\section{HOV Capacity Loss}

General purpose lanes exhibit maximum flows of 2,000 to 2,400 vphpl at a free flow speed of 60 mph $[9,10]$. By contrast, Figure 1 shows that HOV lanes achieve maximum flows of only 1,600 vphpl at a comparatively low speed of $45 \mathrm{mph}$. This is an upfront capacity penalty of at least $20 \%$.

Figure 2 gives a better appreciation of the capacity penalty. The four plots are time series of flow vs. occupancy, averaged every $5 \mathrm{~min}$, from 4-10AM, July 11-14, 2006. The time period includes the morning peak period. Data for two locations on $210 \mathrm{~W}$ are displayed. For each location there are two plots: the one on the top is for the HOV lane, directly below which is the plot for the adjacent GP lane at the same freeway location.

\footnotetext{
${ }^{3}$ California followed Virginia, which allows hybrid vehicles access to I-95. But a January, 2005 Washington Post editorial claimed that as a result "traffic in I-95's HOV lanes is starting to slow to the crawl associated with the regular lanes." The editorial concludes, "Whatever the idea's original logic, it has outlived its usefulness and ought to be dropped" [6]. The Virginia DOT Task Force reportedly has recommended that the exemption for hybrid single occupancy vehicles (SOVs) be allowed to expire in July 2006 [7]. A NY Times columnist predicts a similar fate for California [8].
} 

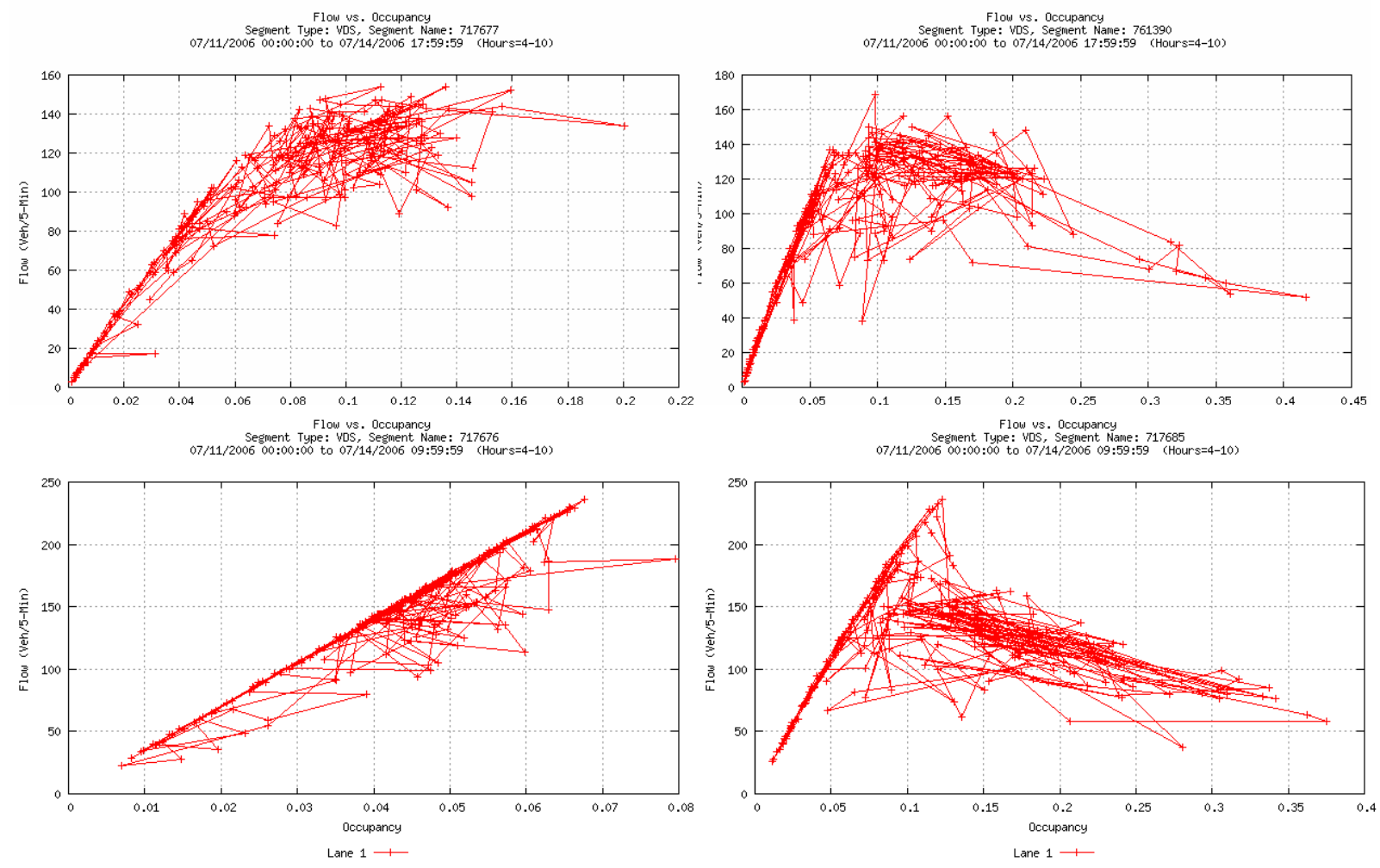

Figure 2: 5-min average flow vs. occupancy at two locations on 210W, 4-10AM, July 11-14, 2006. The top plots are for the HOV lane, directly below are the plots for the adjacent GP lane at the same location.

The maximum flow reached in the HOV lane is $150 \mathrm{veh} / 5 \mathrm{~min}$ or $1,800 \mathrm{vphpl}$, whereas the maximum flow in the GP lane is $220 \mathrm{veh} / 5$-min or 2,640 vphpl, so the capacity of the HOV lane at these locations is 32 percent lower. Second, the speed at which the HOV lane achieves its maximum flow (the speed is proportional to flow/occupancy) is significantly below its speed at lower flows, whereas the GP lane reaches its maximum flow at the same free flow speed as at lower flows.

The reduction in speed with increasing flow in the HOV lane and the resulting capacity penalty may be explained as follows. An HOV lane operates as a one-lane highway, so its speed is governed by the low speed vehicles - the 'snails'. As the GP lane is slower, a faster HOV vehicle cannot pass the slower snail in front of it. As HOV volume increases, there are more snails, leading to a drop in speed. ${ }^{4}$

The snail phenomenon is more evident in data from the San Francisco Bay Area, with its timeactuated HOV lanes. Figure 3 gives scatter plots of 5-minute flows and speed at one location in 880-N on weekdays in August, 2004. For the same lane and location the samples on the left are taken during the HOV actuation period, 4-7PM; those on the right are during 7-9PM, after HOV

\footnotetext{
${ }^{4}$ Three factors may account for the snails: A certain fraction of HOV drivers may prefer to be slow; others may be slow because of the perceived danger from very slow vehicles in the adjacent lane 2; lastly, as congestion in lane 2 worsens, violators may dart into and out of the HOV for short time intervals with increasing frequency, forcing HOV drivers to slow down.
} 
actuation. Snails reduce flow and speed during HOV actuation, but after 7PM they move to the slower right lanes and the maximum flow increases by $18 \%$ from 140 to $170 \mathrm{veh} / 5-\mathrm{min}$; the speed also increases.
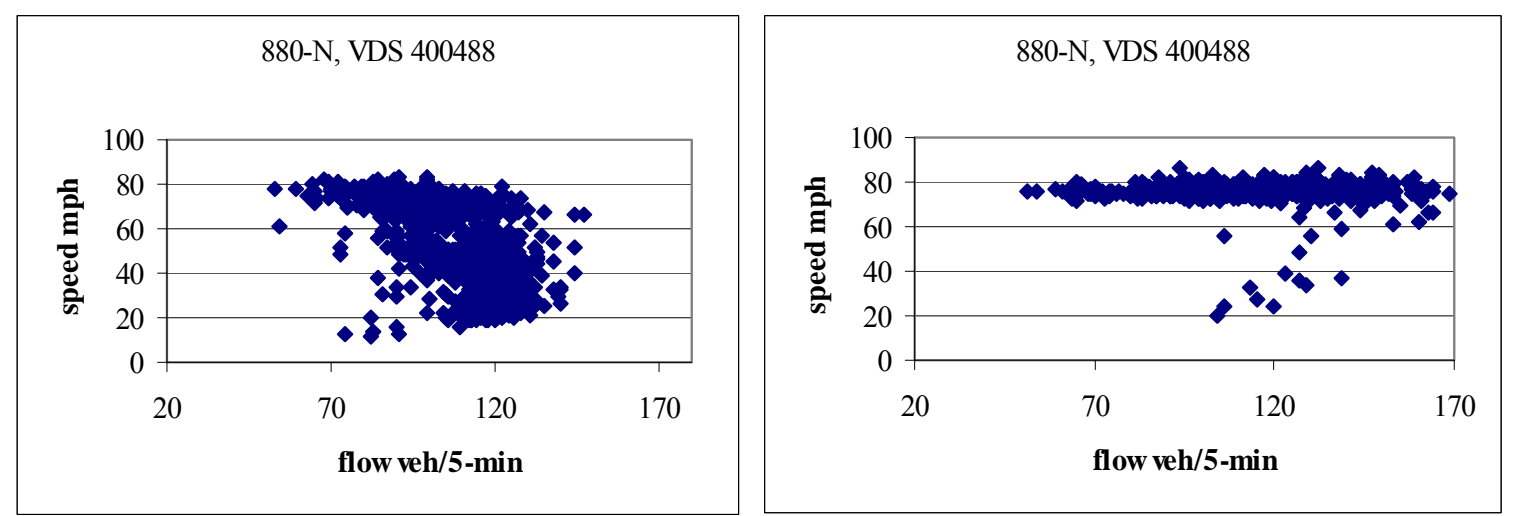

Figure 3 Flow vs. speed during HOV actuation, 4-7 PM (left), and after HOV actuation, 7-9 PM (right), at VDS 400488 on 880-N, August 2004.

\section{Travel Time Savings}

We estimate HOV travel time savings by comparing HOV and adjacent GP lane speeds at the same locations.

Figure 4 is a scatter plot of data from $700+$ locations statewide for 5-6PM on four weekdays, April 3-7, 2006. Each of the 3,700 samples gives the HOV and adjacent GP lane speeds at the same location on one of the four days. Clearly the two speeds are highly correlated (the correlation is 0.76 ), with HOV speeds being slightly higher for low GP lane speeds.

To understand the implications for travel time savings we calculate the HOV and GP lane travel times over the same 10-mile route using a randomly picked speed sample. Figure 5 gives the resulting probability distribution of travel time savings.

The average travel time saving is $1.7 \mathrm{~min}$, the median is $0.7 \mathrm{~min}$, and the standard deviation is $13.9 \mathrm{~min}$. The probability that the savings exceed $4 \mathrm{~min}$ is only 0.19 and the probability is 0.14 that travel along the adjacent GP lane is faster. Caltrans' HOV planning guidelines ask of a proposed HOV facility: "Will the project provide at least one minute of time savings per mile for an average commute trip? A total savings of five to ten minutes is desirable [3, Ch 1, p.4]." The data imply that the vast majority of existing HOV lanes fails the test: Only $15 \%$ of these random 10 -mile routes offer savings of 5 min and only $7 \%$ offer 10 min savings. 


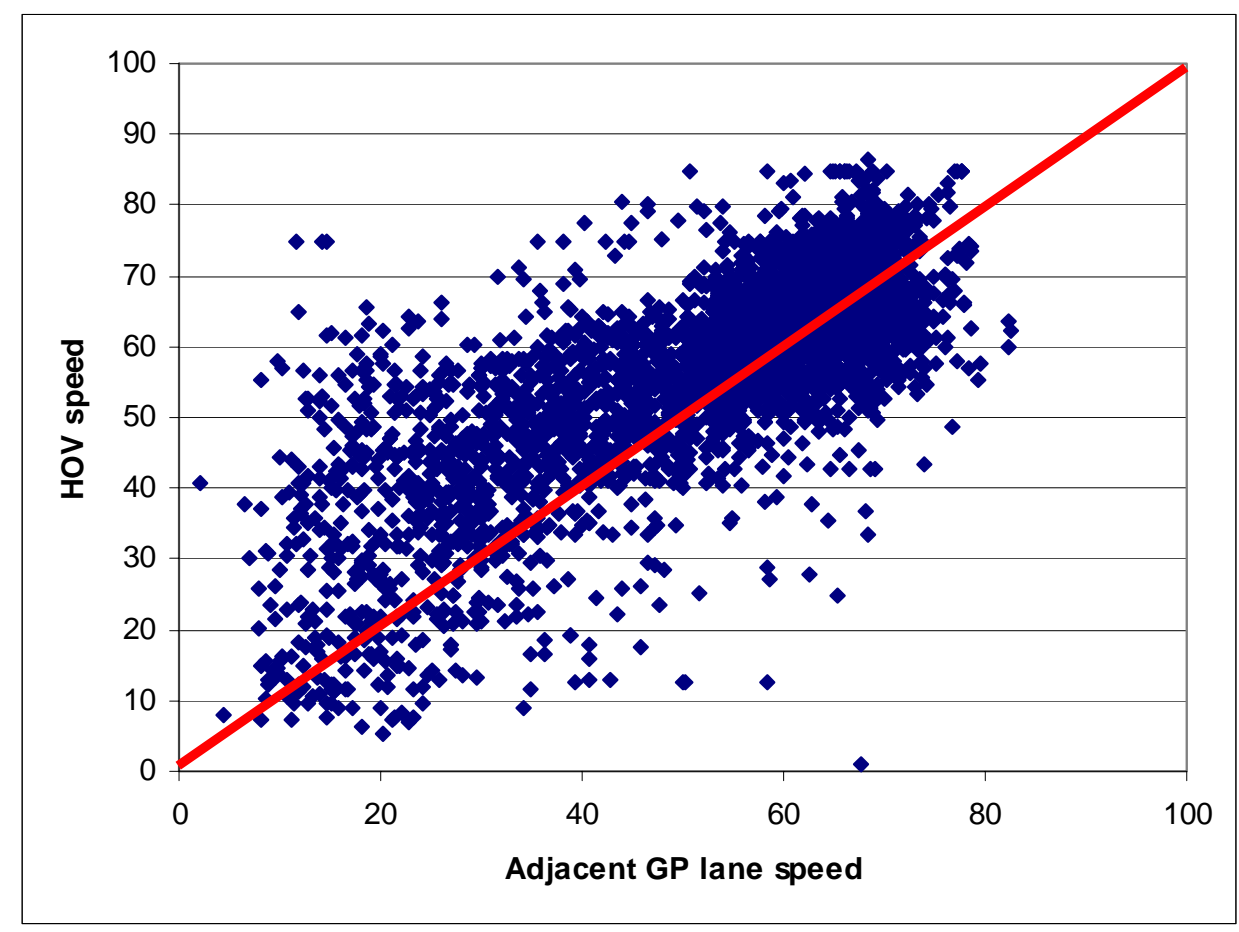

Figure 4 Scatter plot of HOV vs. adjacent GP lane speeds averaged over 5-6PM at 700+ locations on four weekdays, April 3-7, 2006.

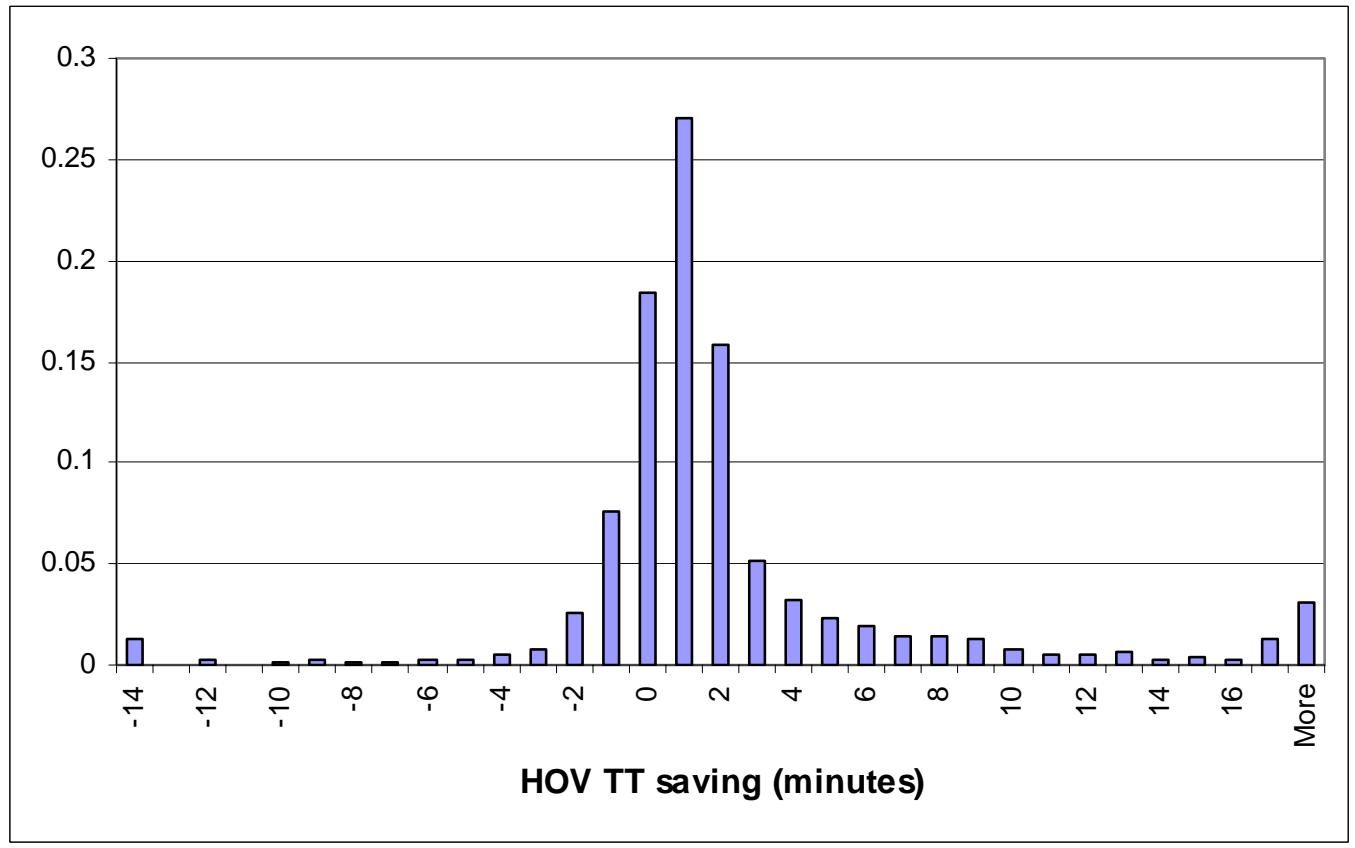

Figure 5 Probability distribution of HOV travel time savings over a random 10-mile route.

While the mean travel time savings offered by HOV is minuscule, HOV travel is more reliable (less variability) than GP lane travel. To see this, we compare travel times along specific routes.

Figure 6 displays the median, $25^{\text {th }}$, and $75^{\text {th }}$ quartiles of travel times along the HOV lane and the adjacent GP lane as a function of departure times on weekdays during Jan 1-May 31, 2006 for an 
18-mile route on I-405. The route is shown on the map. At 7:45AM the median values are 22.5 min for HOV vs. 24 min for GP lane 1, which implies a maximum savings of only $1.5 \mathrm{~min}$ - less than $0.1 \mathrm{~min} / \mathrm{mile}$. (At other times, the savings are lower.) The maximum difference between the $75^{\text {th }}$ quartiles is $5 \mathrm{~min}$, which is larger, whereas the difference between the $25^{\text {th }}$ quartiles is negligible. Thus we may conclude that HOV travel times are slightly more reliable. (The greater reliability is characteristic of the 10 other routes we have examined; it is also explained by Figure 4.)
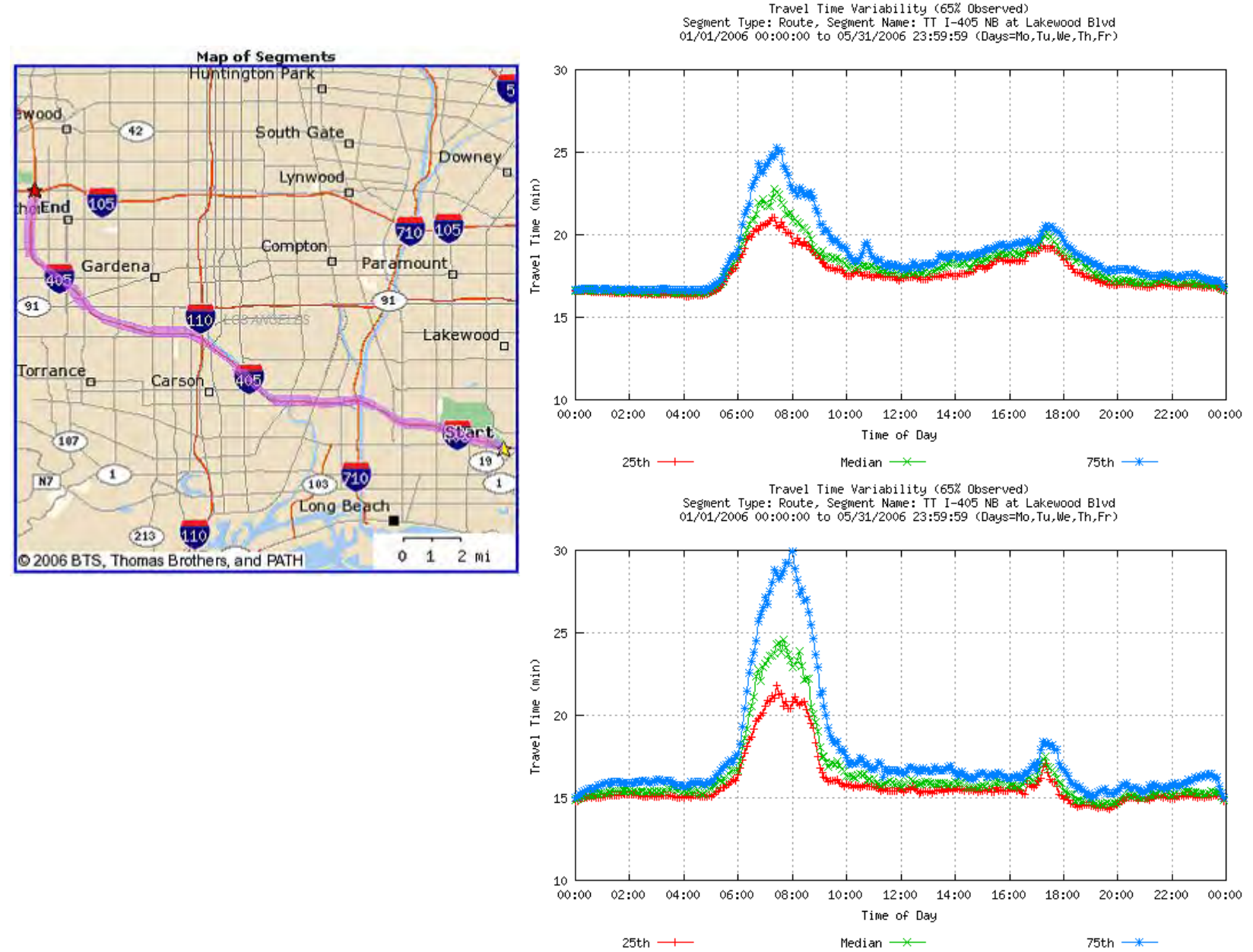

Figure $625^{\text {th }}$, median and $75^{\text {th }}$ quartiles of travel times along HOV (top) and adjacent GP lane (bottom) as a function of departure time for the 18-mile route on I-405, starting at Lakewood Blvd. Data for weekdays, January 1-May 31, 2006.

Figure 7 repeats the displays in Figure 6 for a 14.5-mile route along SR-91E. Although shorter in length, the savings are much larger for this route because of the different design and operation of the facility: This is a two-lane HOV/toll facility, barrier-separated from the GP lanes. The two lanes eliminate snails, and the tolls maintain speed closer to free flow speed of $60 \mathrm{mph}$, even when demand is higher. By contrast the GP lanes are allowed to become congested. 

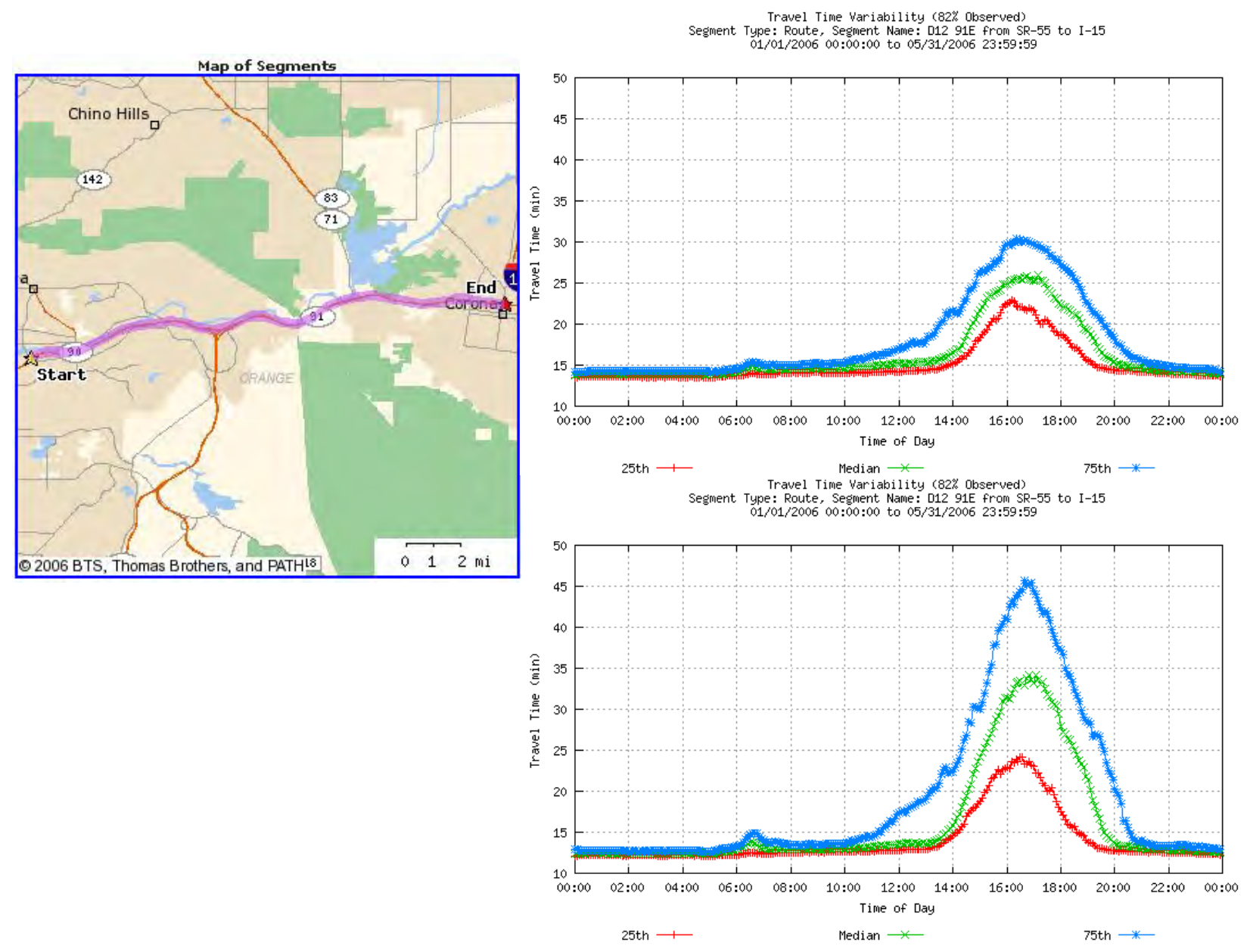

Figure $725^{\text {th }}$, median and $75^{\text {th }}$ quartiles of travel times along HOV (top) and adjacent GP lane (bottom) as a function of departure time for the 14.5-mile route on SR91E, from SR-55 to I-15. Data for weekdays, January 1-May 31, 2006.

\section{Carpooling Incentive}

Since HOV lanes suffer a large loss in vehicle-carrying capacity and offer small travel time savings in comparison with GP lanes, the most important justification for HOV facilities is that they increase person-carrying capacity by encouraging carpooling. We consider person-carrying capacity in the next section, and focus on the carpooling incentive. The hypothesis is that for some travelers the attraction of HOV lanes overcomes the inconvenience of carpooling.

The initial federal 3+ HOV requirement was soon relaxed because of an insufficient number of three-person carpools. The $2000 \mathrm{LAO}$ report reaches no conclusions about the statewide impact of HOV lanes on carpooling because of "lack of data," but says that the national decline in average vehicle occupancy (AVO) from 1.3 in 1977 to 1.14 in 1995 indicates that carpooling has become more inconvenient [1, pp. 1,3].

The 2003 American Community Survey reports that the proportion of work-commute trips in California that are carpooled declined from $13.99 \%$ in 2000 to $12.60 \%$ in 2003 , the difference being statistically significant at the 90 percent level [11]. In the SCAG region, with $660+\mathrm{HOV}$ lane-miles - one-fifth of the nation's — carpooling declined from $14.3 \%$ to $11.4 \%$ between 2000 
and 2004, while the share of drive-alone commuting increased from $73 \%$ to $76.7 \%$. The decline was widespread: from $16.5 \%$ to $12.1 \%$ in San Bernardino County and from $15.6 \%$ to $14.1 \%$ in Riverside County between 2003 and 2004 [12, p. 69, 70]. Over time the attraction of HOV travel appears to be weakening.

Using the long form data provided by the decennial Census in conjunction with the National Household Travel Survey (NHTS) data, a study finds that in $2001,83 \%$ of carpools for homebased work trips had people from the same household (up from 75\% in 1990), 97\% of whom had only household members $\left[13\right.$, p.29]. ${ }^{5}$ So it appears that carpool formation for work trips depends almost entirely on the work locations of members of the same household.

Nevertheless the belief persists that time savings offer a carpooling incentive. For example, in a 2001 Los Angeles telephone survey with 3,273 respondents, 57\% believed that 'travel-time savings' is a common motivation for carpooling; and $82 \%$ of respondents who actually carpooled identified time savings as their main reason for carpooling [14, pp.29-32]. ${ }^{6}$

We devise indirect statistical tests of the theory that travel time savings encourages carpooling. Although HOV travel is not much shorter on average, Figures 4, 5 show considerable daily variation in travel time saving. This leads to the testable hypothesis that an HOV facility's share of daily traffic (vehicle-miles traveled or VMT) increases as the adjacent GP lane speed decreases. We test the hypothesis for the four complete HOV segments in the San Francisco Bay Area listed in Table 2.

\begin{tabular}{|l|l|l|l|l|}
\hline $\begin{array}{l}\text { HOV } \\
\text { segment }\end{array}$ & Limits & $\begin{array}{l}\text { Length } \\
\text { (miles) }\end{array}$ & $\begin{array}{l}\text { Min. } \\
\text { Occ }\end{array}$ & HOV actuation \\
\hline I-80E & Powell St to Rte 4 & 14.1 & 3 & 5-10AM, 3-7PM* \\
\hline I-880N & Mission Blvd to South of Rte 237 & 16.9 & 2 & 5-9AM, 3-7PM* \\
\hline SR-101S & San Mateo Co. Line to Cochrane Rd & 34.8 & 2 & 5-9AM, 3-7PM* \\
\hline SR-101N & Cochrane Rd to San Mateo Co. Line & 34.0 & 2 & 5-9AM*, 3-7PM \\
\hline
\end{tabular}

${ }^{*}$ Peak hours considered

Table 2 The HOV segments

For each HOV segment and each weekday during 2001-2005, we calculate the HOV segment's share $S$ of the vehicle-miles traveled (VMT) in lanes 1 (HOV) and 2 (adjacent GP lane), defined as

$$
S=\frac{V M T_{1}}{V M T_{1}+V M T_{2}} ;
$$

$V M T_{k}$ is the daily peak period traffic in lane $k$ measured in vehicle-miles traveled during the $\mathrm{HOV}$ actuation period. We also calculate $V_{2}$, the speed in lane 2 , averaged over the HOV segment and actuation duration.

Our hypothesis is that HOV share $S$ will increase as lane 2 speed $V_{2}$ decreases. Figure 8 gives a scatter plot of HOV share vs. lane 2 speed for each study segment: Each point shows the average over the HOV actuation AM or PM peak period (as indicated in Table 2) for one weekday. The

\footnotetext{
${ }^{5}$ If home-to-work trips with non-work stops are included, $26 \%$ of carpools included a non-household member in 2001.

${ }^{6} 72 \%$ of 1,300 Bay Area carpool lane users indicated HOV lanes 'greatly reduces' commute travel time [16, p.6].
} 
solid straight line is the least-squares fit to the linear regression $S=\alpha+\beta V_{2}$. Table 3 lists the regression coefficients, together with the fitted values of $S$ for $V_{2}$ equal to 30 and $60 \mathrm{mph}$.

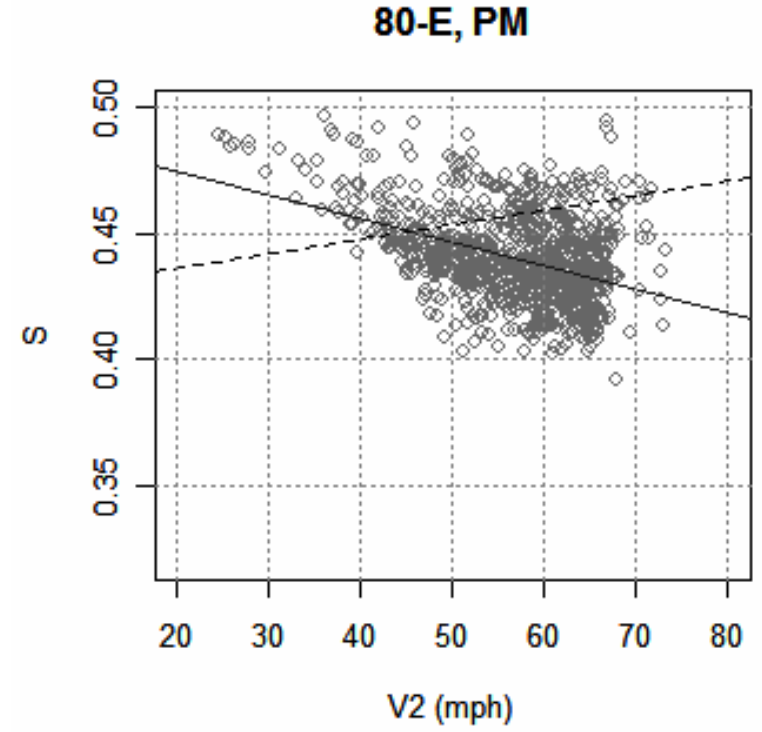

101-S, PM

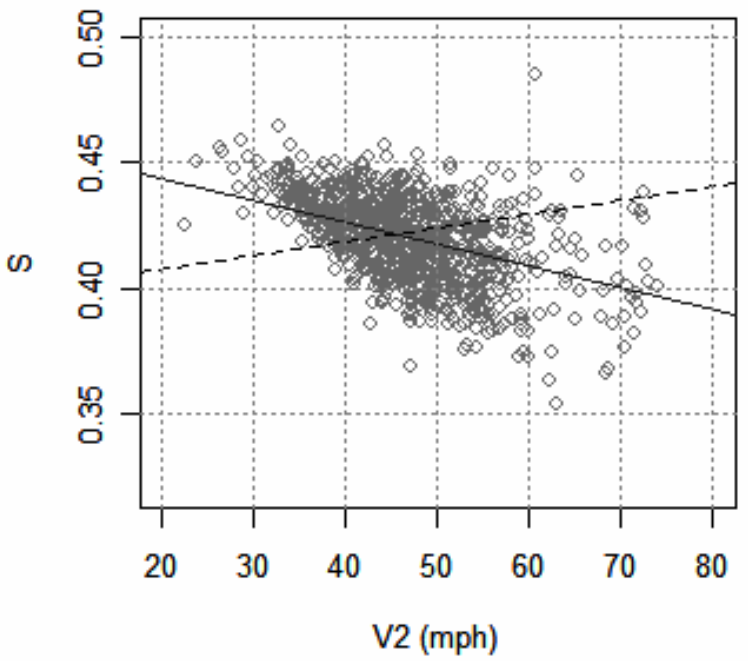

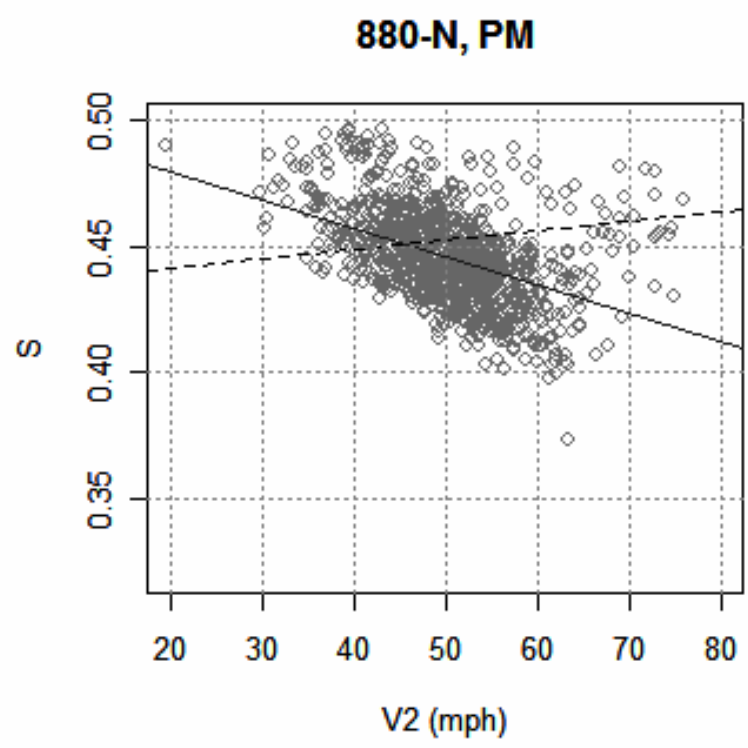

101-N, AM

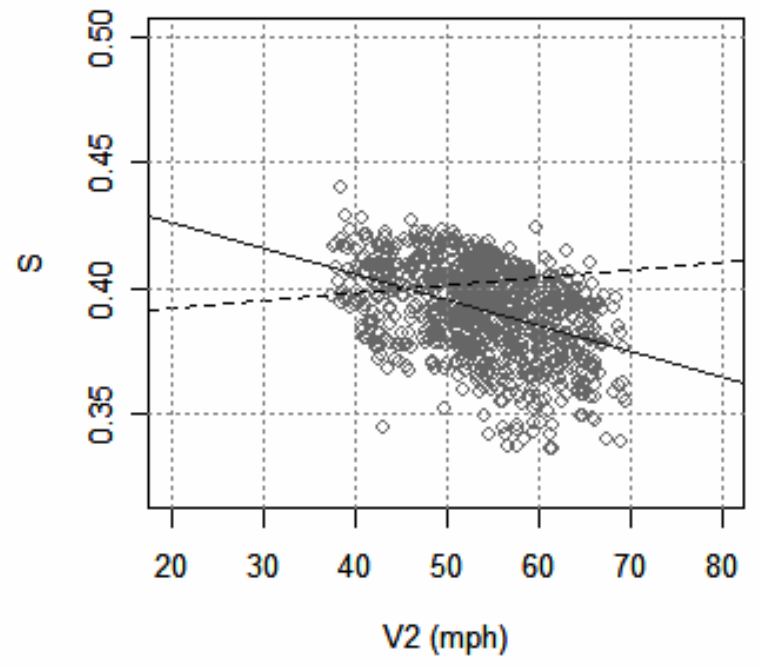

Figure 8 Share of VMT in HOV lane vs. average speed $\left(\mathrm{V}_{2}\right)$ in lane 2 in four HOV segments, for 2001-2005. Each point displays the AM or PM peak for one weekday. Also shown are least squares linear regression lines through data points (solid lines) and adjusted lines (dashed lines). 


\begin{tabular}{|l|l|l|l|l|l|l|l|}
\hline Freeway & $\boldsymbol{\alpha}$ & $\boldsymbol{\beta}$ & $\begin{array}{l}\boldsymbol{S} \text { for } \\
\boldsymbol{V}_{2}=\mathbf{3 0}\end{array}$ & $\begin{array}{l}\boldsymbol{S} \text { for } \\
\boldsymbol{V}_{2}=\mathbf{6 0}\end{array}$ & $\begin{array}{l}\text { Violation } \\
\text { rate (\%) }\end{array}$ & $\begin{array}{l}\boldsymbol{S}_{\text {adj }} \text { for } \\
\boldsymbol{V}_{2}=\mathbf{3 0}\end{array}$ & $\begin{array}{l}\boldsymbol{S}_{\text {adj }} \text { for } \\
\boldsymbol{V}_{2}=\mathbf{6 0}\end{array}$ \\
\hline $\mathrm{I}-80 \mathrm{E}$ & 0.4933 & -0.00093 & 0.465 & 0.437 & $6.5(\mathrm{PM})$ & 0.442 & 0.459 \\
\hline $\mathrm{I}-880 \mathrm{~N}$ & 0.5024 & -0.00112 & 0.469 & 0.435 & $4.4(\mathrm{PM})$ & 0.445 & 0.457 \\
\hline SR-101S & 0.4608 & -0.00086 & 0.435 & 0.409 & $3.0(\mathrm{PM})$ & 0.413 & 0.429 \\
\hline SR-101N & 0.4468 & -0.00103 & 0.416 & 0.385 & $4.5(\mathrm{AM})$ & 0.395 & 0.404 \\
\hline
\end{tabular}

Table 3 Coefficients and selected values of $S=\alpha+\beta V_{2}$

Consider the plot for 101S. In agreement with the hypothesis, there is a (small) downward trend in the scatter plot: As lane 2 speed decreases from 60 to $30 \mathrm{mph}$, the HOV share increases from 0.40 to 0.44 . But even this small increase in HOV share is illusory.

The number of HOV-qualified vehicles or carpools is what we want to measure. It differs in two ways from the number of HOV-using vehicles, which is what we can measure. When speed in lane 2 is high, say $60 \mathrm{mph}$ or more, some HOV-qualified drivers will not use the HOV lane, and so the number of HOV-using vehicles underestimates the number of HOV-qualified vehicles. On the other hand, when speed in lane 2 is low, say $30 \mathrm{mph}$ or less, the number of HOV lane violators will increase, and so the number of HOV-using vehicles overestimates the number of HOV-qualified vehicles. We adjust the share $S$ of $\mathrm{HOV}$-using vehicles to obtain $S_{\text {adj }}$, the share of HOV-qualified vehicles.

Violation rates vary in different HOV segments in the Bay Area (see [15, p.19] and Table 3). Caltrans considers a 10 percent violation rate acceptable [16, p.5]. We assume a 5 percent violation rate when speed in lane 2 is $30 \mathrm{mph}$. We also assume that 5 percent of $\mathrm{HOV}$-qualified drivers do not move into the HOV lane when lane 2 speed is $60 \mathrm{mph}$. The adjusted share $S_{a d j}$ is shown in Table 2. Figure 5 also shows the adjusted regression line for $S_{a d j}$. Evidently, carpooling is unresponsive to short-term (daily) changes in travel- time savings.

It may be that it takes a long time to make carpooling arrangements and so one should not expect a daily carpooling response to travel time savings. We estimate long-term (annual) response. Figure 9 displays box plots ${ }^{7}$ of average speed in lane 2 and share of traffic in HOV lane in each year. Consider the segment in $101 \mathrm{~N}$, AM peak. Speed $V_{2}$ (median and quartiles) in the adjacent GP lane (lane 2) decreases steadily over 2001-2005 even though the HOV annual share $S$ of traffic (median and quartiles) decreased over 2001-2004 as well. Similarly, there is no close correlation between $V_{2}$ and $S$ observable in the other study sites. This finding also repudiates the hypothesis that long term increases in travel-time savings encourage carpooling.

\footnotetext{
${ }^{7}$ In a box plot the heavy horizontal line is the median, the box marks the $25^{\text {th }}$ and $75^{\text {th }}$ quartiles, the whiskers extend the range beyond the box by 1.5 times the inter-quartile range. Samples beyond the whiskers are 'outliers'.
} 

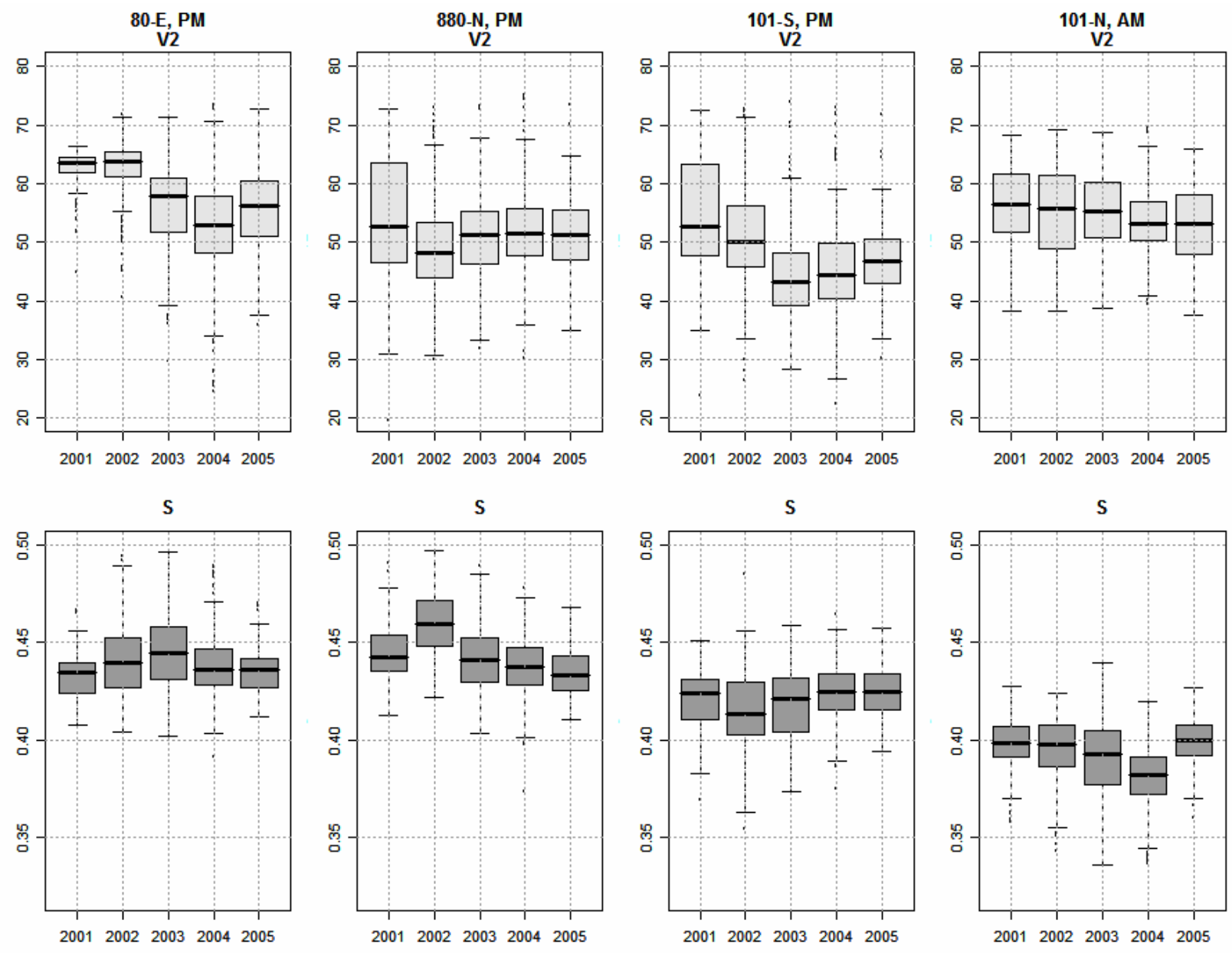

Figure 9 Average speed $\left(V_{2}\right)$ in lane 2 (top) and share of traffic $(S)$ in HOV lane (bottom) for 2001-2005 for the four study segments. Box plots show each year's distribution of daily $S$ or $V_{2}$.

\section{Person Throughput}

HOV lanes are under-utilized, degraded, and yield small average travel time savings that seem not to provide carpooling incentives. It may still be the case that a freeway with an HOV lane carries more persons per hour - has a larger person throughput - than if the HOV lane were replaced by a GP lane. To evaluate this claim we compare two freeway configurations:

$1 \mathrm{HOV}+3 \mathrm{GP}$ (one HOV, 3 GP lanes) vs. 4GP (4 GP lanes). The comparison must account for the fact that person throughput depends on how efficiently the freeway is operated, the capacity of the HOV and GP lanes, and the average vehicle occupancy.

To clarify the issues, we first work out a numerical example comparing the two freeway configurations, under two different operating regimes and two sets of capacity values. 'Efficient Operation', perhaps using ramp metering and traveler information, maintains free flow speed of $60 \mathrm{mph}$ in a GP lane and $45 \mathrm{mph}$ in the HOV lane; 'Inefficient Operation' allows traffic to become congested lowering speed to $30 \mathrm{mph}$ in a GP lane but maintains $45 \mathrm{mph}$ in the HOV lane.

In the 'Moderate Capacity' freeway, flow is $2,000[1,800]$ vphpl in the GP lanes and 1,400 $[1,300]$ vphpl in the HOV lane under Efficient [respectively, Inefficient] Operation. In the 'High Capacity' freeway, flow is 2,400 [2,000] vphpl in the GP lanes and 1,600 [1,500] vphpl in the 
HOV lane under Efficient [respectively, Inefficient] Operation. Lastly, the average vehicle occupancy (AVO) values are 1.1 for GP and 2.1 for HOV vs. 1.2 for the all GP lane freeway. We show later that, based on Bay Area data, the assumed values are defensible.

\begin{tabular}{|c|c|c|c|c|c|c|c|}
\hline & \multicolumn{3}{|c|}{ Moderate Capacity } & \multicolumn{3}{|c|}{ High Capacity } \\
\hline & & $3 \mathrm{GP}$ & $1 \mathrm{HOV}$ & 4GP & $3 G P$ & $1 \mathrm{HOV}$ & $4 G P$ \\
\hline \multirow{7}{*}{$\begin{array}{l}\text { Efficient } \\
\text { Operation }\end{array}$} & VPHPL & 2000 & 1400 & 2000 & 2400 & 1600 & 2400 \\
\hline & AVO & 1.1 & 2.1 & 1.2 & 1.1 & 2.1 & 1.2 \\
\hline & FVPHPL & \multicolumn{2}{|c|}{1850} & 2000 & \multicolumn{2}{|c|}{2200} & 2400 \\
\hline & FPPHPL & \multicolumn{2}{|c|}{2385} & 2400 & \multicolumn{2}{|c|}{2820} & 2880 \\
\hline & FAVO & \multicolumn{2}{|c|}{1.29} & 1.20 & \multicolumn{2}{|c|}{1.28} & 1.20 \\
\hline & Speed & 60 & 45 & 60 & 60 & 45 & 60 \\
\hline & TT & \multicolumn{2}{|c|}{11.03} & 10 & \multicolumn{2}{|c|}{10.99} & 10 \\
\hline \multirow{7}{*}{$\begin{array}{l}\text { Inefficient } \\
\text { Operation }\end{array}$} & VPHPL & 1800 & 1300 & 1800 & 2000 & 1500 & 2000 \\
\hline & FVO & 1.1 & 2.1 & 1.2 & 1.1 & 2.1 & 1.2 \\
\hline & FVPHPL & \multicolumn{2}{|c|}{1675} & 1800 & \multicolumn{2}{|c|}{1875} & 2000 \\
\hline & FPPHPL & \multicolumn{2}{|c|}{2167.5} & 2160 & \multicolumn{2}{|c|}{2437.5} & 2400 \\
\hline & FAVO & \multicolumn{2}{|c|}{1.29} & 1.20 & \multicolumn{2}{|c|}{1.30} & 1.20 \\
\hline & Speed & 30 & 45 & 30 & 30 & 45 & 30 \\
\hline & TT & \multicolumn{2}{|c|}{17.90} & 20 & \multicolumn{2}{|c|}{17.85} & 20 \\
\hline
\end{tabular}

Table 4 Numerical exercise comparing a 3GP+1HOV lane vs. a 4GP lane freeway, with moderate or high capacity, under efficient and inefficient operations.

With these assumed values, one can calculate the freeway vehicles per hour per lane (FVPHPL), the freeway persons per hour per lane (FPPHPL), and the freeway AVO (FAVO) for the four different scenarios. The results are displayed in Table 4. Several conclusions follow.

First, under Efficient Operation, the 4GP freeway carries more persons per hour as well as more vehicles per hour than the $3 \mathrm{GP}+1 \mathrm{HOV}$ freeway. Under Inefficient Operation, the $3 \mathrm{GP}+1 \mathrm{HOV}$ lane carries more persons but fewer vehicles per hour. In either case, the difference in person throughput is less than $0.2 \%$, i.e., the $(1 \mathrm{HOV}+3 \mathrm{GP})$ freeway and the $4 \mathrm{GP}$ freeway provide the same person throughput.

Second, Efficient Operation increases person and vehicle throughput by $10 \%$, compared with Inefficient Operation, which is far more significant than the presence or absence of an HOV lane. In Table 4, TT stands for the average time a person traveling 10 miles would take under the four scenarios. Again, the importance of Efficient Operation is striking: It reduces the travel time by more than $60 \%$.

Third, under Efficient Operation the GP lane at $60 \mathrm{mph}$ is faster than the HOV lane at $45 \mathrm{mph}$. But then drivers will avoid the HOV lane until its flow reduces to 1,200 vphpl (see Figure 1) so that its speed reaches the GP lane's $60 \mathrm{mph}$. This will lead to under-utilization of the HOV lane and a reduction in the person throughput for the $(1 \mathrm{HOV}+3 \mathrm{GP})$ freeway. Thus: If the freeway operation maintains free flow in the GP lanes, the HOV lane will be under-utilized; and the HOV will be well-utilized only if the GP lanes are congested.

Lastly, we pause to consider two arguments. The first argument purports to show that HOV lanes increase person throughput because HOV lanes carry more persons during the peak hour than the 
adjacent GP lanes [14, p. 60; 16, p.8]. (This is also the case in Table 4.) But this is only because HOV lanes 'skim off' carpools from GP lanes. The argument does not address whether an HOV lane increase person throughput overall, which is the goal of HOV facilities.

The second argument says the comparison in Table 4 between efficient and inefficient operation is incorrect because the low speed-low volume in the GP lanes is an indication of high 'demand' rather than inefficient operation. But this is erroneous, because the relation between demand and actual flow or volume depends on operational control. On the one hand, efficient ramp-metering will maintain free flow conditions, even if demand exceeds capacity. On the other hand, once congestion starts, it can persist even if demand falls below capacity.

We now present data that lend credence to the numerical values assumed in Table 4. It is not possible to compare the same freeway under two different configurations, $1 \mathrm{HOV}+3 \mathrm{GP}$ vs. 4GP. But the San Francisco Bay Area freeways come close to this requirement because lane 1 is an HOV lane during the HOV actuation period and a GP lane at other times. So we will compare speed and flows in lanes 1 and 2 in 880-S, during and immediately adjacent HOV actuation periods, at the same location (VDS 400486).
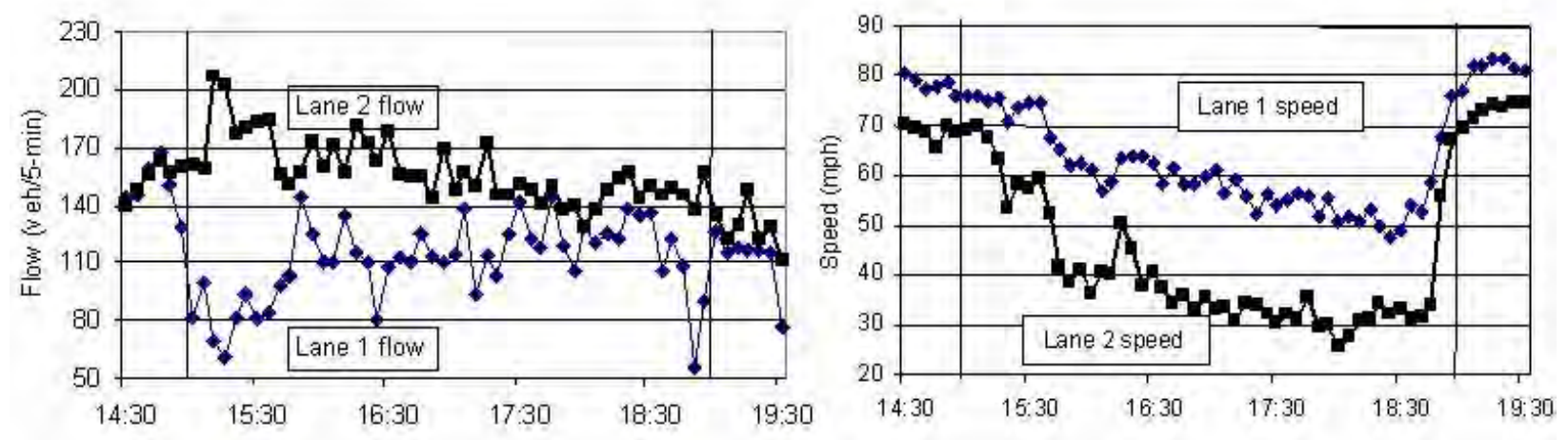

Figure 10 Flows in vehicles/5-min (left) and speeds (right) in lanes 1 and 2 at VDS 400352 on 880-S, August 4, 2004, during HOV actuation (3-7PM) and outside that period.

Figure 10 gives plots of flow (veh/5-min) and speed (mph) in lanes 1 and 2 from 2:30-7:30PM, including the HOV actuation period, 3-7PM, during which lane 1 is an HOV lane. From the speed data, we see that free flow conditions (efficient operation) prevail before 3PM and after 7PM, with (GP) lane 2 flow of 2,000 vphpl. From 5-6:30PM, during the HOV actuation period, both HOV and lane 2 are congested; before 3PM and after 7PM, both lanes 1 and 2 are in free flow.

At 3PM, under free flow, lanes 1 and 2 both reach a flow of $170 \mathrm{veh} / 5$-min or 2,000 vphpl at free flow speed, which supports the value of 2,000 vphpl in Efficient Operation and 'Moderate Capacity'. During 5-6:30 PM the HOV lane has an average volume of $120 \mathrm{veh} / 5-\mathrm{min}$ or 1,440 vphpl and speed of $55 \mathrm{mph}$, while lane 2 has an average flow of $150 \mathrm{veh} / 5-\mathrm{min}$ or 1,800 vphpl and speed of $30 \mathrm{mph}$. These values are similar to those in Table 4 for 'Inefficient Operation' and 'Moderate Capacity'. (Other examples, similar to Figure 10, may be found in [21].)

Lastly, we need the values of AVO. AVO estimates are notoriously unreliable [17] and we rely on various sources. According to [18, p. 66] in the section of 880-S that includes VDS 400486, during the afternoon peak the HOV lane AVO is 2.1 and the AVO on the three non-HOV lanes is 1.1. We used these estimates in Table 4. AVO estimates during HOV de-actuation for 880-S are not available. The Household Travel Survey [19 Table B] gives an AVO of 1.5 for all trips and 
1.1 for home-to-work trips; for the Bay Area, the Metropolitan Transportation Commission gives an AVO of 1.4 for all trips and 1.1 for home-to-work trips [19, Table 8.10]; lastly, the California Life-Cycle Benefit/Cost Analysis Model uses a default of 1.38 for peak period AVO [20, p.2-12]. In Table 4 we used 1.2 for the 4GP freeway, which is conservative.

In summary, the values assumed in Table 4 are defensible, in the absence of direct estimates.

\section{Overall Congestion}

Table 4 allows us to compare the overall congestion delay in the $(1 \mathrm{HOV}+3 \mathrm{GP})$ and the $4 \mathrm{GP}$ freeways. Congestion delay is defined as the additional vehicle-hours traveled (VHT) while driving below $60 \mathrm{mph}$. Under 'Efficient Operation' it is obvious that the 4GP freeway suffers no congestion delay, because all vehicles move at $60 \mathrm{mph}$. In the $(1 \mathrm{HOV}+3 \mathrm{GP})$ freeway, there is congestion delay in the HOV lane where speed is $45 \mathrm{mph}$. However, as noted, this situation cannot persist, because the HOV lane will lose enough flow until its speed reaches $60 \mathrm{mph}$.

Under 'Inefficient Operation' the travel time in the $(1 \mathrm{HOV}+3 \mathrm{GP})$ freeway is slightly smaller than in the 4GP freeway, which implies that the latter creates greater congestion. We may conclude that an HOV lane reduces overall congestion slightly, if the GP lanes become very congested.

\section{Value of HOV Lanes}

The goals of the HOV system are to increase the people-moving capacity of the freeway system by encouraging carpooling; reduce overall congestion; provide travel time savings to HOV users; increase system efficiency; and decrease emissions (not considered in this study).

The data analyzed here indicate that statewide these goals are not met, except that HOV travel times are more reliable than GP travel times and overall congestion is slightly reduced in segments where the GP lanes are very congested. These conclusions hold at three levels of data aggregation that were used: state, district and individual HOV facility.

There are 'niche' uses where HOV lanes do help. One niche comprises the few HOV lanes that carry a significant number of buses or vanpools. The HOV AVO for these would be much higher than shown in Table 4; in turn such high AVO will lead to a larger person throughput. Another niche is created by a 2-lane HOV/HOT facility, which eliminates snails and the resulting capacity loss.

A third niche is illustrated by the Oakland-San Francisco Bay Bridge. The entrance to the bridge is efficiently metered, preventing congestion on the bridge. There is no HOV lane on the bridge itself, but HOVs can bypass the metering. The HOV bypass encourages carpools, which avoid the delay at the metering lights; at the same time the metering achieves the efficiency gains noted in Table 4. This example could be generalized: Impose efficient metering and permit HOV/HOT bypass at the on-ramps.

It appears that federal regulations require HOV lanes in any freeway expansion, and do not permit conversion of an HOV lane to a GP lane. This paper does not address this difficult policy question, except to urge its re-examination.

If HOV lanes are here to stay, the study suggests directions for improving their operation. First, given the large amount of under-utilization (Table 1), it may be better to move towards timeactuated rather than 24-hour HOV restrictions, similar to the Bay Area. The time actuation 
should depend on location and day of week. A detailed study shows systematic day of week and time of day variation in HOV utilization [5].

Second, in the Bay Area, HOV actuation at the same time all along an HOV lane creates a huge congestion in the GP lanes (visible in Figure 10). A much better approach may be to stagger actuation times to minimize this 'shoulder' effect. Such an approach needs investigation.

Lastly, buffered HOV lanes appear not to further HOV goals compared with non-buffered lanes. The possibility that they provide better safety should be investigated.

\section{Conclusion}

To our knowledge this is the first statewide empirical study of California's HOV system. The study finds:

(1) HOV lanes are underutilized: $81 \%$ of HOV detectors measure flows below 1,400 vehicles per hour per lane (vphpl);

(2) Many HOV lanes suffer degraded operations: 18 percent of all HOV-miles during the AM peak hour and 32 percent during the PM peak hour have speeds below $45 \mathrm{mph}$ for more than 10 percent of weekdays;

(3) HOV lanes suffer a 20\% capacity penalty: HOV lanes achieve a maximum flow of 1,600 vphpl at $45 \mathrm{mph}$; in contrast general purpose lanes record maximum flows above 2,000 vphpl at $60 \mathrm{mph}$;

(4) HOV lanes offer small travel time saving: The mean saving over a random 10-mile route traveling on an HOV lane vs. GP lane 1 is 1.7 minutes, the median is 0.7 minutes; however, HOV travel times are more reliable;

(5) Travel time savings do not provide a statistically significant carpooling incentive;

(6) A system with one HOV and three GP lanes does not carry the same number of persons per hour as a system with four GP lanes;

(7) HOV lanes reduce overall congestion slightly when the GP lanes are allowed to become congested.

Despite these negative findings, HOV facilities can play an important role in a well-managed overall freeway system in California. In particular, they can be useful if there is a significant number of buses or vanpools; as a 2-lane HOV/HOT facility, which eliminates snails and the resulting capacity loss; and, with efficient metering, as a HOV/HOT bypass at the on-ramps.

From these findings, we arrive at three major conclusions:

- As currently operated, the HOV system does not meet its goals except in niche uses, which are important in themselves, but not in the overall state system;

- By operating the freeway system efficiently - maintaining free flow traffic - much more is to be gained than by adding HOV lanes. Indeed efficient operations will reduce the value of HOV lanes, which will become under-utilized;

- An efficient operation combined with HOV bypass at the on-ramps will permit reaping the gains of efficiency together with significant travel time savings for HOVs.

There are plans to extend California's HOV system. The San Francisco Bay Area seeks to increase its current $270 \mathrm{HOV}$ lane-miles by an additional 230 lane-miles [16, Table 1], at a cost of $\$ 3.7$ billion. The plan builds on the premise, "Carpooling, vanpooling and express bus services have become increasingly more important to meeting the mobility needs of the region... 
$[16, p .2]$ " The premise seems false: carpooling is unlikely to grow. A far more cost-effective solution is to work toward an efficient freeway system.

\section{Acknowledgement}

This report summarizes the joint research of Jaimyoung Kwon and Pravin Varaiya. We are grateful to many people for critical comments on earlier drafts of this paper, especially Walt Brewer, Tim Buchanan, Fred Dial, Tarek Hatata, Lisa Klein, Dave Mootchnik, Karl Petty, Robert Poole, Asfand Siddiqui, Alex Skabardonis, Ramakrishna R. Tadi, Martin Wachs, and John Wolf.

The contents of this paper reflect the views of the authors who are responsible for the facts and the accuracy of the data presented herein. The contents do not necessarily reflect the official views of or policy of the California Department of Transportation. This paper does not constitute a standard, specification or regulation.

\section{References}

1 Legislative Analyst's Office. HOV lanes in California: Are they achieving their goals?, January 2000. www.lao.ca.gov/2000/010700 hov/010700 hov lanes.html. Accessed July 7, 2004.

2 Freeway Performance Measurement System (PeMS). http://pems.eecs.berkeley.edu. Accessed June 21, 2006.

3 California Department of Transportation, Division of Traffic Operations. High Occupancy Vehicle Guidelines. http://www.dot.ca.gov/hq/traffops/systemops/hov/hov_sys/guidelines/. Accessed July 8, 2006.

4 U.S. House of Representatives. Safe, Accountable, Flexible, Efficient Transportation Equity Act: A Legacy for Users, Public Law 109-59. http://www.washingtonwatchdog.org/documents/cong_reports/house/109/housereport109_20 3.html Accessed July 13, 2006.

$5 \mathrm{~J}$ Kwon. HOV Lane Operation and the Impact of Introducing Hybrids Vehicles to HOV lanes in California. Draft final report prepared for California Department of Transportation. September 6, 2005.

6 Washington Post. The Hybrid's Free Ride. Editorial, p. B06. January 16, 2005.

7 FastLane, Spring 2005 Issue. http://managed-lanes.tamu.edu. Accessed June 22, 2005.

8 J. Tierney. The road to hell is clogged with righteous hybrids. NY Times, Opinion, August 30, 2005.

9 Z. Jia, P. Varaiya, C. Chen, K. Petty, and A. Skabardonis. Maximum throughput in LA freeways occurs at $60 \mathrm{mph}$ v.4. January 16, 2001. http://pems.eecs.berkeley.edu/Resources/Papers/throughput4.pdf Accessed July 8, 2006.

10 C. Chen and P. Varaiya. Max. flow in D12 occurs at $60 \mathrm{mph}$. October 2001. http://pems.eecs.berkeley.edu/Resources/Papers/D12maxflow.pdf Accessed July 24, 2006.

11 U.S. Census Bureau. American Community Survey 2003 Multi-Year Profile: California, Table 3. http://www.census.gov/acs/www. Accessed June 21, 2005

12 Southern California Association of Governments. The State of the Region 2005: Measuring Regional Progress, December 2005. http://www.scag.ca.gov/publications/pdf/2006/SOTR05/SOTR05 FullReport.pdf. Accessed July 20, 2006. 
13 McGuckin, N. and N. Srinivasan. The Journey-to-Work in the Context of Daily Travel. www.trb.org/conferences/censusdata/Resource-Journey-to-Work.pdf . Accessed June 21, 2005

14 The PB Study Team. HOV Performance Program Evaluation Report. Los Angeles County Metropolitan Transportation Authority, 2002.

15 California Department of Transportation, District 4, Oakland. 2001 District 4 HOV Report. February 2002.

16 DKS Associates. 2002 High Occupancy Vehicle (HOV) Lane Master Plan Update. Prepared for Metropolitan Transportation Commission, Caltrans District 4 and the California Highway Patrol Golden Gate Division, March 2003.

17 Levine, N. and M. Wachs. Methodology for Vehicle Occupancy Measurement. Report submitted to the California Air Resources Board and the California Department of Transportation (Office of Traffic Improvement), 1994.

18 California Department of Transportation, District 4, Office of Highway Operations. HOV lanes in the Bay Area, 2002.

19 California Department of Transportation. 2000-2002 California Statewide Household Travel Survey, 2002.

20 Booz Allen \& Hamilton. California Life-Cycle Benefit/Cost Analysis Model, 1999.

21 Chen, C., J. Kwon and P. Varaiya. An empirical assessment of traffic operations. H.S. Mahmassani (Ed) Proceedings, International Symposium on Transportation and Traffic Theory, pp 105-124, Elsevier, 2005.

22 Chen, C., J. Kwon, A. Skabardonis and P. Varaiya. Detecting errors and imputing missing data for single loop surveillance systems. Transportation Research Record, 1855, 160-167, 2003. 